\title{
Would You Be Happier If You Were Richer? A Focusing Illusion
}

by Daniel Kahneman, Princeton University Alan B. Krueger, Princeton University and NBER David Schkade, University of California, San Diego Norbert Schwarz, University of Michigan Arthur A. Stone, Stony Brook University

CEPS Working Paper No. 125

May 2006

Research support provided by the Princeton University Center for Economic Policy Studies is gratefully acknowledged. 
Most people believe that they would be happier if they were richer, but survey evidence on subjective well-being is largely inconsistent with that belief. Subjective well-being is most commonly measured by questions that ask people, "All things considered, how satisfied are you with your life as a whole these days?" or "Taken all together, would you say that you are very happy, pretty happy, or not too happy?" Such questions elicit a global evaluation of one's life. An alternative method asks people to report their feelings in real time, which yields a measure of experienced happiness. Surveys in many countries conducted over decades indicate that, on average, reported global judgments of life satisfaction or happiness have not changed much over the last four decades, in spite of large increases in real income per capita. While reported life satisfaction and household income are positively correlated in a cross-section of people at a given time, increases in income have been found to have mainly a transitory effect on individuals' reported life satisfaction. (1-3) Moreover, the correlation between income and subjective well-being is weaker when a measure of experienced happiness is used instead of a global measure. This article reviews recent evidence that helps interpret these observations.

When people consider the impact of any single factor on their well-being -- not only income -- they are prone to exaggerate its importance; we refer to this tendency as the focusing illusion. Income has even less effect on people's moment-to-moment hedonic experiences than on the judgment they make when asked to report their satisfaction with their life or overall happiness. These findings suggest that the standard survey questions by which subjective wellbeing is measured (mainly by asking respondents for a global judgment about their satisfaction or happiness with their life as a whole) may induce a form of focusing illusion, by drawing people's attention to their relative standing in the distribution of material well-being. More importantly, the focusing illusion may be a source of error in significant decisions that people make. (4) 
Evidence for the focusing illusion comes from diverse lines of research. For example, Strack and colleagues (5) reported an experiment in which students were asked: (i) "How happy are you with your life in general?" and (ii) "How many dates did you have last month?" The correlation between the answers to these questions was -.012 (not statistically different from 0) when they were asked in the specified order, but the correlation rose to 0.66 when the order was reversed with another sample of students. The dating question evidently caused that aspect of life to become salient and its importance to be exaggerated when the respondents encountered the more general question about their happiness. Similar focusing effects were observed when attention was first called to respondents' marriage (6) or health (7). One conclusion from this research is that people do not know how happy or satisfied they are with their life in the way they know their height or telephone number. The answers to global life satisfaction questions are constructed only when asked (8), and are therefore more susceptible to the focusing of attention on different aspects of life.

To test the focusing illusion regarding income we asked a sample of working women to estimate the percentage of the time that they were in a bad mood in the preceding day. Respondents were also asked to estimate the percentage of time people with pairs of various life circumstances (Table 1), such as high- and low-income, typically spend in a bad mood. Respondents' predictions were compared to the actual reports of mood provided by participants in the survey with the relevant circumstances. The focusing illusion predicts a systematic overestimation of the effect of life circumstances on mood.

Table 1 presents the mean percentage of time that members in each group reported spending in a bad mood in the preceding work day. It also shows the corresponding mean predictions offered by the entire group (including individuals whose reports were included in the actual mood column). The predictions were biased in two respects. First, the prevalence of bad 
mood was generally overestimated. Second, consistent with the focusing illusion, the predicted prevalence of a bad mood for people with undesirable circumstances was grossly exaggerated. For example, the average respondent predicted that people with income below $\$ 20,000$ per year would spend 58 percent of their time in a bad mood, compared with 26 percent for those with income above $\$ 100,000$ per year; the actual percentages were 32 percent and 20 percent, respectively.

The focusing illusion explains why the results of well-being research are often counterintuitive. The false intuitions likely arise from a failure to recognize that people do not continuously think about their circumstances, whether positive or negative. Schkade and Kahneman (9) noted that, "Nothing in life is quite as important as you think it is while you are thinking about it." Individuals who have recently experienced a significant life change -- e.g., becoming disabled, winning a lottery, or getting married -- surely think of their new circumstances many times each day, but the allocation of attention eventually changes, so that they spend most of their time attending to and drawing pleasure or displeasure from experiences such as having breakfast or watching television. (10) However, they are likely to be reminded of their status when prompted to answer a global judgment question such as, "How satisfied are you with your life these days?"

The correlation between household income and reported life satisfaction or happiness with life as whole (assigned an integer value) in national samples typically range from 0.15 to 0.30. (11) Table 2 illustrates the relationship between global happiness and income for 2004 with data from the General Social Survey. Those with incomes over $\$ 90,000$ are nearly twice as likely to report being "very happy" as are those with incomes below $\$ 20,000$, although there is hardly any difference between the highest income group and those in the \$50,000-89,999 bracket. 
There are reasons to believe that the modest cross-section correlation between income and judgments of life satisfaction or overall happiness overstates the effect of income on subjective well-being. First, increases in income have mostly a transitory effect on individuals' reported life satisfaction $(2,12)$. Second, large increases in income for a given country over time are not associated with increases in average subjective well-being. Easterlin (1), for example, found that the fivefold increase in real income in Japan between 1958 and 1987 did not coincide with an increase in the average self-reported happiness level there. Third, although average life satisfaction in countries tends to rise with GDP per capita at low levels of income, there is little or no further increase in life satisfaction once GDP per capita exceeds $\$ 10,000$. (3)

Fourth, when subjective well-being is measured from moment to moment -- either by querying people in real time using Ecological Momentary Assessment (EMA) (13) or by asking them to recall their feelings for each episode of the previous day using the Day Reconstruction Method (DRM) (14) -- income is more weakly correlated with experienced feelings such as momentary happiness averaged over the course of the day (henceforth called duration-weighted or experienced happiness) than it is with a global judgment of life satisfaction or overall happiness, or a global report of yesterday's mood.

For example, the correlation between life satisfaction and household income was 0.32 in data we collected from 745 women in Columbus, Ohio in May 2005. Two other measures of subjective well-being were constructed for the same sample: the duration-weighted average happiness rating for all episodes of the previous day and respondents' own global estimate of the percent of time they spent in a good or bad mood in the previous day. The correlations of income with the global report of good mood and with the duration-weighted average of more detailed reports of happiness were 0.20 and 0.06 , respectively; see Table 3 . Both correlations are 
significantly lower than the correlation between income and life satisfaction, and significantly different from each other. (15) Correlations with other life circumstances exhibit the same pattern: a weaker correlation with duration-weighted average happiness across episodes of the day than with global life satisfaction. (16)

An analysis of EMA data also points to a weak and sometimes perverse relationship between experienced affect and income. Specifically, we examined EMA data from the Cornell Worksite Blood Pressure study of 374 workers, who were queried about their intensity of six feelings on a $0-3$ scale every $25 \mathrm{~m}$ or so during an entire workday. $(17,18)$ The correlation between personal income and the average happiness rating during the day was just $0.01(\mathrm{p}=0.84)$, while family income was significantly positively correlated with ratings of Anger/Hostile $(\mathrm{r}=.14)$, Anxious/Tense $(\mathrm{r}=.14)$ and Excited $(\mathrm{r}=.18)$. Thus, higher income was associated with more intense negative experienced emotions and greater arousal, but not greater experienced happiness.

Why does income have such a weak effect on subjective well-being? There are several explanations, all of which may contribute to varying degrees. First, Duesenberry (19), Easterlin (2), Frank (20) and others have argued that relative income rather than the level of income affects well-being - earning more or less than others looms larger than how much one earns. Indeed, much evidence indicates that rank in the income distribution influences life satisfaction. (21-23) As society grows richer, the average rank does not change, so the relative income hypothesis could explain the stability of average subjective well-being despite national income growth. The importance placed on relative income may also account for the stronger correlation between income and global life satisfaction than between income and experienced affect, as life satisfaction questions probably provoke a reflection on relative status that is not present in 
moment-to-moment ratings of happiness. The relative income hypothesis cannot by itself explain why a permanent increase in an individual's income has a transitory effect on her wellbeing, as relative standing would increase. However, the increase in relative standing can be offset by changes in the reference group: After a promotion, the new peers increasingly serve as a reference point, making the improvement relative to one's previous peers less influential. (24)

Second, Easterlin $(1,2)$ argues that individuals adapt to material goods, and Scitovsky (25) argues that material goods yield little joy for most individuals. Thus, increases in income, which are expected to raise well-being by raising consumption opportunities, may in fact have little lasting effect because the consumption of material goods has little effect on well-being above a certain level of consumption or because of hedonic adaptation. (26) Moreover, people's aspirations adapt to their possibilities and the income that people say they need to get along rises with income, both in a cross-section and over time. (27)

Finally, we would propose another explanation: as income rises, people's time use does not appear to shift toward activities that are associated with improved affect. Subjective wellbeing is connected to how people spend their time. Table 4 presents our tabulations from the American Time Use Survey on how the average individual's waking time is divided among various types of activities. The last two rows show the average experienced happiness and tense/stress rating associated with each activity based on the Columbus DRM survey. People with greater income tend to devote relatively more of their time to work, compulsory non-work activities (such as shopping and childcare) and active leisure (such as exercise), and less of their time to passive leisure activities (such as watching TV). On balance, the activities that highincome individuals spend relatively more of their time engaged in are associated with no greater happiness, on average, but with slightly higher tension and stress. 
The results in Table 4 also highlight the possible role of the focusing illusion. When someone reflects on how more income would change subjective well-being, they are probably tempted to think about spending more time in leisurely pursuits such as watching a large-screen plasma TV or playing golf, but in reality they should think of spending a lot more time working and commuting and a lot less time engaged in passive leisure (and perhaps a bit more golf). By itself, this shift in time use is unlikely to lead to much increase in experienced happiness, although it could increase tension and one's sense of accomplishment and satisfaction.

Despite the weak relationship between income and global life satisfaction or experienced happiness, many people are highly motivated to increase their income. In some cases, this focusing illusion may lead to a misallocation of time, from accepting lengthy commutes (which are among the worst moments of the day) to sacrificing time spent socializing (which are among the best moments of the day). (28) An emphasis on the role of attention helps to explain both why many people seek high income - because they over predict the increase in happiness due to the focusing illusion and because changes in relative income are associated with strong emotional responses - and why the long-term effects of these changes are relatively small -because attention eventually shifts to less novel aspects of daily life. 
Table 1. The Focusing Illusion: Exaggerating the effect of various circumstances on well-being Percentage of Time in a Bad Mood

\begin{tabular}{|c|c|c|c|c|c|}
\hline \multirow[b]{2}{*}{ Variable } & \multirow[b]{2}{*}{ Group $^{2}$} & \multicolumn{4}{|c|}{ Percentage of Time in a Bad Mood } \\
\hline & & Actual $^{1}$ & Predicted & $\begin{array}{c}\text { Actual } \\
\text { Difference }\end{array}$ & $\begin{array}{l}\text { Predicted } \\
\text { Difference }^{2}\end{array}$ \\
\hline Household & $<\$ 20,000$ & 32.0 & 57.7 & 12.2 & $32.0^{*}$ \\
\hline Income & $>\$ 100,000$ & 19.8 & 25.7 & & \\
\hline Woman Over & alone & 21.4 & 41.1 & -1.7 & $13.2 * *$ \\
\hline 40 Years Old & married & 23.1 & 27.9 & & \\
\hline Supervision & definitely close & 36.5 & 64.3 & 17.4 & $42.1^{* *}$ \\
\hline At Work & definitely not close & 19.1 & 22.3 & & \\
\hline Fringe & No health insurance & 26.6 & 49.7 & 4.5 & $30.5 * *$ \\
\hline Benefits & Excellent benefits & 22.2 & 19.2 & & \\
\hline
\end{tabular}

${ }^{* *}$ Indicates that predicted difference is significantly larger than actual difference at $\mathrm{p}<.001$.

1 "Now we would like to know overall how you felt and what your mood was like yesterday. Thinking only about yesterday, what percentage of the time were you: in a bad mood__ $\%$, a little low or irritable _ $\%$, in a mildly pleasant mood_ $\%$, in a very good mood_ $\%$. Bad mood reported here is the sum of the first two response categories. A parallel question was then asked about yesterday at work. Bad mood at work was used for the supervision comparison.

${ }^{2}$ Data are from the Texas sample used in Kahneman, et al. (29). For actual column, the preceding day was a workday. Reading down each column, sample sizes are Household Income: Actual $(n=64,59)$, Predicted $(n=83,83)$; Woman over 40 years old: Actual $(n=82,221)$, Predicted $(\mathrm{n}=85,87)$; Supervision at Work: Actual $(\mathrm{n}=75,237)$, Predicted $(\mathrm{n}=84,84)$; Fringe Benefits: Actual $(\mathrm{n}=96,211)$, Predicted $(\mathrm{n}=83,85)$. 
Table 2: Distribution of Self-Reported Happiness by Family Income, General Social Survey, 2004

"Taken all together, how

would you say things are

these days--would you

say that you are very

happy, pretty happy, or

not too happy?"

or

\begin{tabular}{cl}
\hline Under & $\$ 20,000-$ \\
$\$ 20,000$ & $\$ 49,999$
\end{tabular}

Family Income

\begin{tabular}{|c|c|c|c|c|}
\hline not too happy?" & $\$ 20,000$ & $\$ 49,999$ & $\$ 50,000-\$ 89,999$ & and over \\
\hline Not too happy & $17.2 \%$ & $13.0 \%$ & $7.7 \%$ & $5.3 \%$ \\
\hline Pretty happy & $60.5 \%$ & $56.8 \%$ & $50.3 \%$ & $51.8 \%$ \\
\hline Very happy & $22.2 \%$ & $30.2 \%$ & $41.9 \%$ & $42.9 \%$ \\
\hline
\end{tabular}

Notes: . Sample size is 1,173 individuals. Observations are weighted by sample weights. 
Table 3: Correlations between selected life circumstances and subjective well-being measures

\begin{tabular}{lccc}
\multicolumn{1}{c}{ Characteristic } & $\begin{array}{c}\text { Life } \\
\text { Satisfaction }\end{array}$ & $\begin{array}{c}\text { Percent of } \\
\text { Day in } \\
\text { Good Mood }\end{array}$ & $\begin{array}{c}\text { Duration- } \\
\text { Weighted } \\
\text { "Happy" }\end{array}$ \\
\hline Household Income & $.32^{*}$ & $.20^{*}$ & .06 \\
Married & $.21^{*}$ & $.15^{*}$ & .03 \\
Education & $.16^{*}$ & $.13^{*}$ & .02 \\
Employed & $.14^{*}$ & $.13^{*}$ & .01 \\
BMI & $-.13^{*}$ & $-.08^{*}$ & -.06 \\
\hline
\end{tabular}

Notes: $\mathrm{n}=745$, Columbus, Ohio DRM sample. ${ }^{*}$ indicates $\mathrm{p}<0.05$.

Percent of the day in good mood is from two questions of the form: "We would like to know how you feel and what mood you are in when you are at home [at work]. When you are at home, what percentage of the time are you in a bad mood $\%$, a little low or irritable__ $\%$, in a mildly pleasant mood _ \%, in a very good mood__ \%. A parallel question was asked about their time at work. The last two response categories were added together to obtain the percentage of time in a good mood, and the home and work questions were averaged to produce the good mood variable.

Duration-weighted "happy" is the average of each person's duration-weighted average rating of the feeling happy over episodes of the day, where 0 refers to "not at all" and 6 refers to "very much," and each individual's responses were weighted by the duration of the episode. 
Table 4: Percent of Time Spent in Various Activities by Family Income, 2004 and Average Affective Ratings During Activities

\begin{tabular}{|c|c|c|c|c|c|c|}
\hline Family Income & $\begin{array}{l}\text { Active } \\
\text { Leisure }\end{array}$ & Eating & $\begin{array}{l}\text { Passive } \\
\text { Leisure }\end{array}$ & Compulsory & $\begin{array}{r}\text { Work \& } \\
\text { Commute }\end{array}$ & Other \\
\hline \multicolumn{7}{|l|}{ Men } \\
\hline$<\$ 20,000$ & $6.6 \%$ & $6.6 \%$ & $34.7 \%$ & $20.8 \%$ & $29.1 \%$ & $2.1 \%$ \\
\hline$\$ 20,000-99,999$ & $8.1 \%$ & $7.2 \%$ & $26.4 \%$ & $21.8 \%$ & $35.4 \%$ & $1.1 \%$ \\
\hline$\$ 100,000+$ & $10.2 \%$ & $8.6 \%$ & $19.9 \%$ & $23.6 \%$ & $36.9 \%$ & $0.8 \%$ \\
\hline \multicolumn{7}{|l|}{ Women } \\
\hline$<\$ 20,000$ & $5.3 \%$ & $5.7 \%$ & $33.5 \%$ & $35.6 \%$ & $18.5 \%$ & $1.4 \%$ \\
\hline$\$ 20,000-99,999$ & $7.5 \%$ & $6.7 \%$ & $23.8 \%$ & $34.3 \%$ & $26.7 \%$ & $1.0 \%$ \\
\hline$\$ 100,000+$ & $9.1 \%$ & $7.0 \%$ & $19.6 \%$ & $35.9 \%$ & $27.3 \%$ & $1.1 \%$ \\
\hline \multicolumn{7}{|l|}{ Feelings (0-6) } \\
\hline Happy & 4.67 & 4.45 & 4.21 & 4.04 & 3.94 & 4.25 \\
\hline Tense/Stressed & 0.92 & 1.17 & 1.30 & 1.80 & 2.00 & 1.61 \\
\hline
\end{tabular}

Notes: Time allocation is weighted-average percentage of the day for each sampled observation from the American Time Use Survey (30). Weighted average of weekday (5/7) and weekend $(2 / 7)$ is presented. Sample consists of 3,917 men and 4,944 women age 18-60. Last two rows are computed from a DRM survey of 810 women in Columbus, Ohio in May 2005; if multiple activities were performed during an episode, the activity refers to the one that was selected as "most important" at the time. 


\section{References}

1. R. Easterlin, Journal of Economic Behavior and Organization 27, 35 (1995).

2. R. Easterlin, Building a better theory of well-being. Discussion Paper No. 742 (IZA, Bonn, Germany, 2003).

3. R. Layard, Happiness: Lessons from a new science (Penguin Press, London, 2005).

4. D. Gilbert, Stumbling on happiness (Knopf, New York, 2006).

5. F. Strack, L. Martin, \& N. Schwarz, European Journal of Social Psychology 18, 429 (1988).

6. $\quad$ N. Schwarz, F. Strack, \& H. Mai, Public Opinion Quarterly 55, 3 (1991).

7. D. Smith, N. Schwarz, T. Roberts, \& P. Ubel, Quality of Life Research (in press).

8. N. Schwarz \& F. Strack, in Well-being. The foundations of hedonic psychology, D. Kahneman, E. Diener, \& N. Schwarz, Eds. (Russell Sage Foundation, New York, NY, 1999), pp. 61-84.

9. D. Schkade \& D. Kahneman, Psychological Science 9, 340 (1998).

10. D. Kahneman \& R. H. Thaler, Journal of Economic Perspectives 20, 221 (2006).

11. E. Diener \& R. Biswas-Diener, Social Indicators Research 57, 119 (2002).

12. B. Frey \& A. Stutzer, Happiness and economics: How the economy and institutions affect well-being. (Princeton University Press, Princeton, NJ, 2002).

13. A. Stone \& S. Shiffman, Annals of Behavioral Medicine 16, 199 (1994).

14. D. Kahneman, A. Krueger, D. Schkade, N. Schwarz, \& A. Stone, Science 306, 1176 (2004).

15. In general, we find that the retrospective report of mood on the previous day, which is a global evaluation, shares variance both with the global measures of life satisfaction and with disaggregated measures of emotional experience at particular times.

16. The higher correlation of these circumstances with satisfaction than with durationweighted happiness is probably not a result of greater noise in the duration-weighted happiness measure than in life satisfaction. We conducted a reliability study of the DRM that asked the same questions of 229 women two weeks apart, and found about the same two-week serial correlation in duration-weighted happiness as in life satisfaction for the respondents. 
17. P. Schnall, J. Schwartz, P. Landsbergis, K. Warren, \& T. Pickering, Psychosomatic Medicine 60, 697 (1998).

18. The adjectives were Anger/Hostile, Anxious/Tense, Overwhelmed, Excited, Happy and Tired. All 6 adjectives were asked at 9 of the sites with 296 people, and another site with 78 people asked only the first three (negative) adjectives.

19. J. Duesenberry, Income, saving, and the Theory of Consumer Behavior (Harvard University Press, Cambridge, MA, 1949).

20. R. Frank, Luxury fever (Princeton University Press, Princeton, NJ, 1999).

21. A. Clark \& A. Oswald, Journal of Public Economics 61, 359 (1996).

22. A. Ferrer-i-Carbonell, Journal of Public Economics 89, 997 (2005).

23. E. Luttmer, Journal of Economics 120, 963 (2005).

24. W. Runciman, Relative deprivation and social justice (University of California Press, Berkeley, CA, 1966).

25. T. Scitovsky, The joyless economy (Oxford University Press, Oxford, 1976).

26. S. Frederick \& G. Lowenstein, in Well-being: The foundations of hedonic psychology, D. Kahneman, E. Diener, \& N. Schwarz, Eds. (Russell-Sage, New York, 1999), pp. 302329.

27. B. Van Praag \& P. Frijter, in Well-being: The foundations of hedonic psychology, D. Kahneman, E. Diener, \& N. Schwarz, Eds. (Russell-Sage, New York, 1999), pp. 413433.

28. See Stutzer and Frey (2004) for evidence on the misallocation of commuting time and Kahneman et al (2004) on the hedonic experience of commuting and socializing.

29. D. Kahneman, E. Diener, \& N. Schwarz, Well-being: The foundations of hedonic psychology (Russell Sage Foundation, New York, 1999).

30. Time-use survey - First results announced by BLS, United States Department of Labor, USDL 04-1797.

31. The authors thank Marie Connolly, Molly Fifer and Amy Krilla for research assistance, and the Hewlett Foundation, the National Institute of Aging and the Woodrow Wilson School and Center for Economic Policy Studies of Princeton University for financial support. 